\title{
Happiness and its molecular fingerprints
}

\author{
Nicole Probst-Hensch ${ }^{1,2}$
}

Received: 14 October 2016/Accepted: 4 January 2017/Published online: 18 February 2017

(C) The Author(s) 2017. This article is published with open access at Springerlink.com

\begin{abstract}
Happiness and well-being are in part heritable, but modifiable traits. The promotion of well-being and happiness, much like the primary prevention of noncommunicable diseases (NCD), will become increasingly important in a world that is facing an NCD epidemic due to demographic aging and urbanization. The costs for the often lifelong treatment of NCDs are already high and may increase further with the arrival of expensive personalized medicine. The effective promotion of happiness at the individual and population level in order to guide policy requires a causal and mechanistic understanding of its modifiable determinants. With more than half of the world's population living in cities, it becomes, for example, important to understand how environmental, social, and lifestyle characteristics of urban life influence well-being. Yet, the correlation between many of these factors and the fact that they act in concert poses a large challenge in causal inference. The -omics biomarkers which form a pillar of personalized medicine are at the same time essential research instruments of modern-day observational epidemiology. The paper discusses how they can be applied to overcome the challenges researchers face in studies on the association of complex risk and protective patterns with specific well-being phenotypes and their relation to diseases. Important concepts are discussed in the context of well-being that were recently developed by epidemiologists to stimulate more investments into the understanding of the modifiable part of health (e.g., Exposome; Meet-in-the-Middle; Mendelian Randomization) to match the huge investments that went into genetic research.
\end{abstract}

Nicole Probst-Hensch

nicole.probst@unibas.ch

1 Swiss Tropical and Public Health Institute, Basel, Switzerland

2 University of Basel, Basel, Switzerland 
Keywords Happiness · Well-being · Biomarker · Genetic - Genomic · Exposome

\section{JEL Classification I1}

\section{Happiness and well-being are modifiable}

The World Happiness Report 2016 Update (http://worldhappiness.report/) ranks 156 countries by their level of happiness. The fact that most countries routinely include in their national surveys at least a basic indicator of happiness reflects the value that these days countries and governments give to the promotion of happiness for their people. Happiness is a proxy of "human development" at the societal level. Happiness is modifiable-we are not doomed by our genes to be unhappy. Four important aspects provide supportive evidence for the long-term modifiability of happiness: First, the inequality in the level of happiness observed between and within countries; second, the time trends in country-specific happiness; third, the nation-specific shapes of the curves plotting Cantril's Ladder Score of happiness on age (Steptoe et al. 2015); and fourth, migrants' happiness level is closer to the happiness level of residents in the destination rather than in the home country (Frank et al. 2015). According to the most recent World Happiness Report, inequalities in happiness are increasing within countries and are themselves an important determinant of a countries happiness level. According to the report, about $75 \%$ of the difference in happiness between countries and regions is explained by the following six key factors: GDP per capita; healthy years of life expectancy; social support; trust; perceived freedom to make life decisions; and generosity. Yet, this reflects an ecological association rather than an association of parameters collected at the individual level. Furthermore, determinants of happiness are likely to differ by the happiness phenotype studied. The construct validity of "happiness" is difficult to demonstrate. There are reasons and interests in exploring the determinants of the different facets of happiness and well-being. Steptoe et al. (2015), for example, listed the following three dimensions of well-being: life satisfaction (evaluative); recent happiness or sadness (hedonic); and purpose (eudaimonic), but other definitions exist.

\section{The challenges in identifying the modifiable determinants of happiness}

In order to promote happiness in an efficient manner, it is essential to understand the modifiable factors influencing phenotypes of well-being at the individual level. The challenges ahead are comparable to the ones faced by chronic disease prevention. Happiness, like mental health or age-related diseases, is the result of the multifactorial influence of risk and protective factors related to aspects including genetics, personality, personal and family history, lifestyle and health as well as political, structural, social and environmental circumstances of living. The fraction of happiness attributable to specific risk and protective patterns depends on the specific well-being dimension used. The following are some of the challenges in identifying modifiable 
determinants of happiness phenotypes: First, the effects of each determinant alone are small and require large studies to be detected with sufficient statistical power. Second, only longitudinal studies allow disentangling cause and effect of correlated states of well-being such as aging, happiness, health, and life conditions. Prospective studies with repeated interrogation of their participants allow for a more clear time-sequence of events to mitigate the problem of reverse causation. Third, the potentially long latency of effects accentuates the risk of exposure misclassification, particularly if exposure is assessed retrospectively. Consistent with the existence of very long latencies or long-lasting effects is, for example, the association between childhood trauma and inflammatory gene expression in the blood later in adulthood (Levine et al. 2015). Fourth, the identification of causal risk and protective factors of relevance to the promotion of happiness is hindered by confounding which may be accentuated by the complexity of the happiness construct. For example, with more than half of the world's population living in an urban environment, it is relevant to understand the influence of components of life in the city on happiness and well-being (Lambert et al. 2015). Yet, urban life goes along with traffic noise and air pollution, altered social networks, artificial light pollution, lack of and access to different types of greenspace, and altered lifestyle. These factors can all be highly correlated, albeit in a spatial-specific context, which complicates the identification of confounders (Foraster 2013).

\section{Clinical versus public health and epidemiologic research utility of -omics biomarkers}

Personalized medicine is a very promising approach to improve health outcomes at an individual level. However, the existing unmet needs and health inequalities may widen further with personalized medicine because of its high costs, with obvious repercussions at an individual and population level on perceived happiness (Abettan 2016).

Personalized health builds on the unprecedented advances in high-through-put processing of big data as it becomes available from technological advances in eHealth, imaging, and molecular-omics analysis. The genetic and genomic characterization of diseases has proven clinical utility in refining disease classification, such as observed in the field of oncology where, for example, non-small cell lung cancer has evolved from a single disease phenotype to a collection of molecular sub-phenotypes with different novel treatment options. In contrast, the clinical utility of premorbid risk prediction toward the materialization of the promised shift from reactive to more preventive medicine is lagging behind expectations when diseases with complex etiology are concerned. Over the past decade, the intense effort to elucidate the genetic architecture of complex diseases etiologies in the context of hundreds of genome-wide association studies (GWAS) has uncovered thousands of gene variants associated firmly with these diseases, albeit only explaining in most cases a small proportion of disease risk (Rappaport 2016). While there is clear clinical utility of genetic testing for monogenetic disorders (e.g., utility for family planning, neonatal screening, timely and targeted preventive and therapeutic intervention), the clinical utility of genetic risk prediction for complex diseases remains uncertain in most cases. The expected 
individual value of genetic risk prediction in chronic, age-related diseases lies in a stimulus for altered behavior in persons at risk for a chronic disease. Yet, according to a recent meta-analysis, evidence for alterations in screening attendance or lifestyle (e.g., smoking, nutrition, alcohol consumption) stimulated by a genetic test is clearly lacking (Hollands et al. 2016). Would it make sense to predict the likelihood of being unhappy in specific situations through a genetic test? While currently gene tests for predicting unhappiness and its sub-phenotypes that are sufficiently predictive at the individual level do not exist, such a test could in fact be of value in certain clinical situations to capture vulnerability to long-lasting distress following a diagnosis; to predict which patients will suffer from mood disturbances when taking a specific chemotherapeutic regimen; to predict pharmacological response to the treatment of disturbed well-being; and therefore in the end to identify patients benefitting from interventions to sustainably increase happiness and well-being (Sprangers et al. 2010). Even if such tests were identified in the future, it will be important to test and demonstrate their clinical validity and utility.

What is often overlooked in discussions about the current limitations in the clinical utility of -omics biomarkers is their utility for public health and epidemiologic research that aims to uncover the modifiable exogenous determinants of health and disease. Biomarkers offer unprecedented opportunities for overcoming some of the research challenges in this endeavor as listed above. As biomarkers of extrinsic exposure, they allow capturing exposures inside the body in the sense of biomonitoring and reflect the dose that actually entered the body to exert its biological action. Depending on the biomarker's half-life, they may also capture exposure history such as in the case of smoking, which leaves epigenetic marks in the blood that are still visible more than 20 years after smoking cessation (Shenker et al. 2013). These characteristics of biomarkers have the potential to decrease the problem of exposure misclassification. As biomarkers of phenotype or disease, they offer the possibility to improve the classification of neighboring happiness dimensions, of understanding of molecular profiles underlying sub-phenotypes and of how these molecular profiles are altered by exogenous modifiable exposures.

Finally, as biomarkers of susceptibility such as in the case of genetic risk markers they help identify subjects more likely to develop a disease phenotype in response to an adverse risk pattern.

The value of biomarkers has gained tremendous momentum with the advent of -omics technologies that allow investigating disease etiologies and risk factor mechanism agnostically without the limitations of current biological understanding. The first agnostic approaches to disease understanding were GWAS, in which thousands of genetic variants are tested for disease association. The penalty of very stringent $p$ values to account for spurious results due to multiple testing was overcome in part by the formation of large research consortia that combined phenotype and genome-wide data in the context of large meta-analysis to increase statistical power and detect true effects when they existed. The biggest value of GWAS was the novel insight they provided in part into the molecular pathways underlying specific diseases. But given that genetic variation alone explains a very small percentage of most common complex diseases, the exposome concept was put forward first by C. Wild (2005) to point to the importance of matching efforts invested into genetic research 
with efforts invested into a novel exposure understanding. The exposome has been defined as the totality of external and internal exposures impacting on health and diseases over the life course. The personalized health technologies which extend from -omics biomarkers to the personalized sensoring of lifestyle, social contacts, and environmental contexts and also include the availability of high-resolution geographic information system (GIS) data now facilitate capturing the internal and external geographic information system of humans (Topol 2014) and thus an individual's exposome. We now have at hands the tools to characterize a person's molecular profile, environment, behavior, and well-being at any specific point in time which allows for new and hypothesis-free approaches as a further step toward causal inference and mechanistic understanding of modifiable health risks in the context of exposome-wide association studies that profile exposures also in the form of biomarkers (Rappaport 2016).

From a public health perspective, research into the urban exposome and its relation to health and well-being is of high priority. By now, more than half of the world's population is living in an urban environment. Urbanization is a major driver of the epidemiological transition from the predominance of communicable to noncommunicable diseases. The changes in the health profile combined with changes in the environmental, occupational, and social context accompanying life in the city also impact on well-being and happiness (Mehrdadi et al. 2016). On the one hand, the health relevance of the urban exposome can be studied one risk factor and one health outcome at a time, using -omics biomarkers to improve causal and mechanistic understanding of these relationships. On the other hand, the -omics biomarkers could be applied to the search for molecular pathways that interlink several exposures and several diseases. Such pathways, if they exist and are modifiable, are of considerable public health relevance, because they would account for a substantial disease and risk factor burden (Fig. 1). The following evidence supports the existence of public health relevant pathways-pathways that mediate the association of several risk factors with several diseases: First, the incidence of several chronic diseases increases in parallel with aging. Second, a group of centenarians exists that is often free of any chronic disease until very old age, whereas persons dying at a younger age are often faced with co-morbidities (Ailshire et al. 2015). Third, biological pathways exist that have been linked to a diversity of risk factors prevalent in urban environments and at the same time to numerous age-related diseases. That is true for oxidative stress and systemic lowgrade inflammation, two interrelated mechanisms. Oxidative stress and low-grade systemic inflammation are increased by several factors such as smoking, air pollution, and obesity, and they are elevated in patients with different diseases such as COPD, diabetes, or cardiovascular disease (Probst-Hensch 2010). A proinflammatory state called inflammaging is present in older persons (Franceschi and Campisi 2014). Oxidative stress and inflammation may contribute to the parallel increase of chronic disease with aging through the peroxidation of nucleic acids, bases, lipids, proteins, and carbohydrates. It may then ultimately be the accumulation of damage to biomolecules in various cells and organs which explains the parallel increase in the incidence of several age-related diseases in response to inflammatory and oxidative risk factors. If that was true, if in fact oxidative stress 


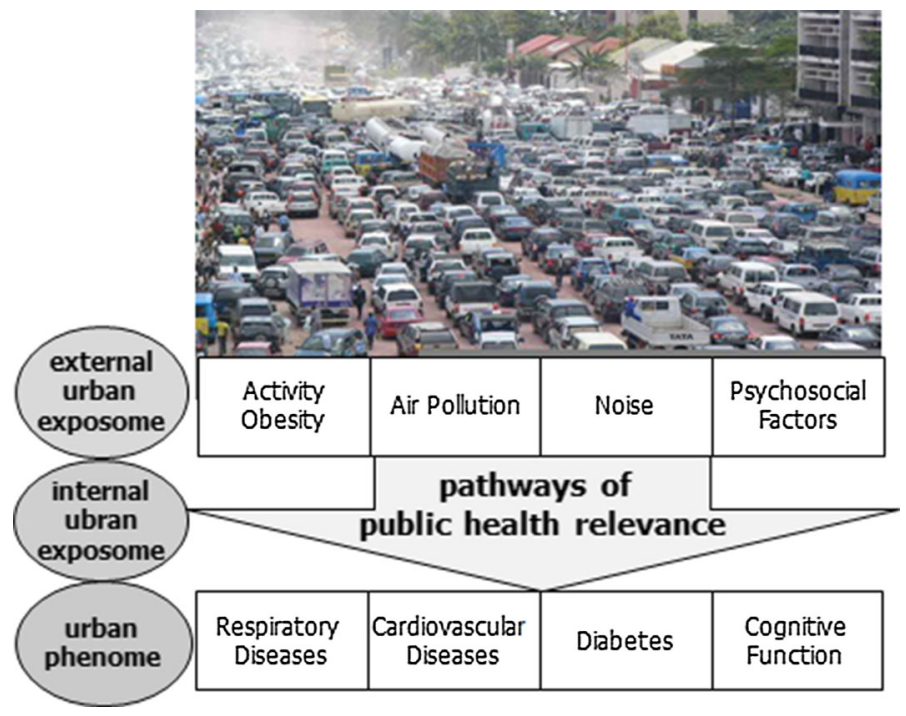

Fig. 1 Urban exposome and phenome - interlinked by public health relevant pathways?

was at least in part a causal mediator between the urban exposome (several exposures common to life in the city) and phenome (several diseases common in populations living in the city and achieving older ages), then the modification of oxidative stress through primary prevention would be of high priority. An example for a cost-effective intervention to decrease oxidative stress could be the recommendation for a higher intake of antioxidant food items.

The impact of life in the city or components thereof and the mediating role of oxidative stress and systemic low-grade inflammation on happiness and well-being phenotypes and their downstream health outcomes have not been studied in the context of an exposome approach. Yet, it is well established that emotional experiences influence and are influenced by circulating pro-inflammatory cytokines. Pro-inflammatory stressors and emotions both activate the hypothalamic-pituitaryadrenal (HPA) axis and/or the sympathetic nervous system (SNS) (Tuck et al. 2016). Of interest in the context of the urban exposome is the fact that traffic noise, for example, is thought to impact on the same systems and thereby exerts its health effects (Recio et al. 2016).

The following two paragraphs outline the research value of biomarkers in the context of studying the influence of components of urban life on happiness phenotypes and their health consequences, with a particular focus on the role of traffic noise, light pollution, and obesity on well-being and its potential downstream health cardiometabolic consequences (Fig. 2).

\subsection{Biomarkers toward understanding the happiness exposome}

Biomarkers can be used at several steps when investigating the happiness exposome. 


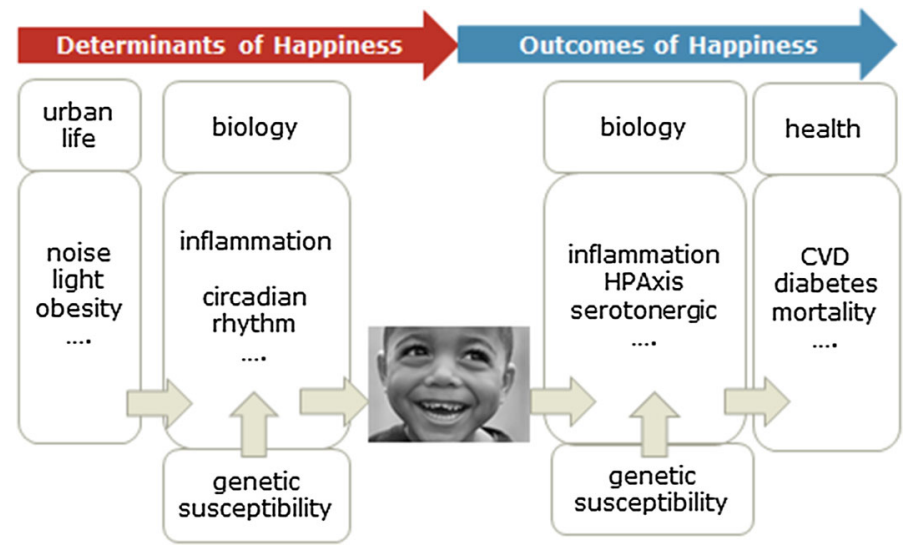

Fig. 2 Molecular fingerprints in the pathway from life in the city to happiness and health

\subsubsection{A first research question is on the causal role of inflammation on well-being and happiness}

On the one hand, obesity (Festa et al. 2001), traffic-related air pollution and noise (Münzel et al. 2016), psychosocial stress (Das 2016), as well as light exposure and associated sleep disturbance (McAlpine and Swirski 2016) have all been associated with low-grade systemic inflammation. On the other hand, pro-inflammatory profiles have been associated with phenotypes of well-being (Janicki-Deverts et al. 2007; Steptoe et al. 2008; Tuck et al. 2016). But because low-grade systemic inflammation is related to numerous other exposures and phenotypes, the assessment of its causal role in well-being is hampered by potential confounding. An approach to improve causal understanding is the use of genetic variants as instrumental variables in the context of the Mendelian randomization principle. To capture chronic inflammation well, the biomarker C-reactive protein (CRP) has a couple of attributes (Pepys and Hirschfield 2003). Circulating CRP has been associated with various quality-of-life indicators (Nowakowski 2014; Hamer and Chida 2011). Circulating CRP is in part genetically determined. Unlike circulating CRP, genetic determinants of CRP are randomized to gametes at the time point of their formation and they are therefore not likely subject to confounding. Any association between CRP gene variants and happiness-related phenotypes would provide evidence for a causal effect in the above-cited associations of systemic inflammation with well-being. In fact, a recent Mendelian randomization approach supports a causal role of low-grade systemic inflammation in dispositional optimism in overweight and obese persons (Rius-Ottenheim et al. 2012).

\subsubsection{A second research question is whether light pollution in the city impacts on well-being and whether any observed association is mediated by alterations in the circadian rhythm}

Circadian rhythms are generated by endogenous biological clocks that are regularly set or modulated by environmental cues such as the daily light-dark cycle. Artificial 
light-pollution affects circadian rhythmicity by impacting on melatonin secretion. Melatonin in addition to its sleep regulatory effect also exhibits anti-oxidative properties (Gabriel et al. 2017). Findings from the Gross National Happiness study in Buthan point to the role of sleep in self-reported health status, an important indicator of a high happiness score (Sithey et al. 2017). Both disturbances in circadian rhythm and in sleep have been associated with mortality and cardiovascular morbidity, and with mental health disorders and with psychological well-being (Espie et al. 2016; Harb et al. 2015). The endogenous clock for circadian rhythm is determined at its core by transcriptional-translational feedback loops consisting of two transcription factors (CLOCK/NPAS2; BMAL1/BMAL2) that activate the transcription of target genes such as PERIOD (PER)1, PER2, PER3, and CRYPTOCHROME (CRY)1 and CRY2 (Yurtsever et al. 2016). Genetic variation in PER3 was shown to impact on melatonin suppression in response to light. A cross-over design study examined eighteen healthy young men with different genotypes in PER3, and the authors could demonstrate that sleep responses to nonimage-forming light depended on the PER3 genotype (Chellappa et al. 2014). It would be of interest to follow up on this finding by asking the question whether an association between light pollution and well-being-related phenotypes was also modified by genetic variants in PER3. If so, the gene-environment interaction would lend support to the hypothesis of a mediating role of altered circadian rhythm in the pathway from light pollution to well-being.

\subsubsection{A third research question is about the mechanisms which may mediate an association between traffic noise and well-being}

Today's option for hypothesis-free approaches to studying exposure mechanisms is of particular interest for noise exposure, which exerts broad health effects, yet remains very poorly understood at the molecular level. Exposure to noise from traffic is thought to exert its health effects through conscious pathways (e.g., noise annoyance) as well as sub-conscious pathways (e.g., heart rate variability), both of which may influence the HPA axis and lead to allostatic load ("the cost of chronic exposure to fluctuating or heightened neural or neuroendocrine response resulting from the repeated or chronic environmental challenge that an individual reacts to as being particularly stressful"-McEwen and Stellar 1993) (Recio et al. 2016). Annoyance from noise impacts on worries and emotions and thus well-being (van den Berg et al. 2015). The health effects of traffic noise in part overlap with the health effects of air pollution raising concerns about potential confounding and causality of noise effects (Foraster 2013). Circulating -omics biomarkers that are associated with both, the external exposure of interest and the phenotype of interest (after adjustment for the external exposure of interest) can inform about molecular pathways mediating exposure effects on health (Chadeau-Hyam et al. 2011). This meet-in-the-middle approach to improve mechanistic and causal understanding of exposure disease relationships is currently applied toward understanding of the air and water pollution exposome (Vineis et al. 2016). Of interest, when 280 blood metabolites were investigated for mediating the effect of air pollution on lung function, the meet-in-the-middle approach pointed to alpha-tocopherol, the main 
form of anti-oxidative Vitamin $\mathrm{E}$ in the circulation (Menni et al. 2015). The untargeted meet-in-the-middle approach using -omic biomarkers has not been applied to noise effects and to investigate how the noise and air pollution exposome differ.

\subsection{Biomarkers toward understanding the happiness-related phenome}

Biomarkers can be used at several steps of studying the molecular patterns underlying different happiness phenotypes and mediating their health consequences.

\subsubsection{A first research question is about molecular profiling of different happiness- related phenotypes}

This parallels the molecular profiling of chronic disease phenotypes such as, for example, asthma (Wenzel 2016). The refined classification of phenotypes is important for identifying modifiable determinants of happiness and well-being and to improve the construct validity of these phenotypes. Combining phenotypes with different etiological origins into a single outcome may mask risk factor effects in subgroups and bias the associations. The comparison of -omics marker profiles in accessible biospecimens such as blood between different well-being phenotypes can inform about molecular differences. The molecular profiles of well-being phenotypes can also be studied in a dynamic approach over a period of months, because phenotypes like well-being are likely also to be characterized by short- and medium-term molecular fluctuations of molecular networks. This concept has recently been applied to a single participant who was characterized in-depth over the period of 532 days for dynamics of brain function and their relation to psychological and biological parameters (Poldrack et al. 2015). Molecular profiles related to well-being can also serve as endpoints in intervention studies for promoting happiness, as recently shown for a Yoga intervention that was able to reduce inflammation-related biomarkers among fatigued breast cancer survivor (Irwin et al. 2014) and family dementia care givers (Black et al. 2013). Finally, genetic determinants of happiness-related phenotypes can provide new insights into the molecular basis of happiness. Twin studies point to an important influence of genetic background for well-being. According to recent meta-analysis of heritability estimates for well-being, based on data from over 55,000 individuals, the average heritability of satisfaction with life was $32 \%$ (95\% confidence intervals (29-35)Bartels 2015). Much like in candidate gene studies for chronic diseases, the interrogation of genetic variation in genes related to biological pathways of hypothesized relevance to quality of life produced inconsistent evidence (Sprangers et al. 2014). Genome-wide data produced in the context of sufficiently powered study consortia and allowing for a hypothesis-free search is more promising. Data from the UK Biobank were used for assessing whether polygenetic risk scores found in genome-wide association studies on personality traits such as extraversion and neuroticism were associated with phenotypes of well-being. The authors reported positive associations between extraversion-related gene scores and well-being measures, and inverse associations between neuroticism-relate gene scores and life 
satisfaction (Weiss et al. 2016). Results from the first genome-wide association study on overall well-being and happiness were published only recently by the Social Science Genetic Association Consortium (www.ssgac.org). Data from nearly 300,000 persons were studied for genetic association with subjective well-being, depressive symptoms, and neuroticism (Okbay et al. 2016). Variants in three different genes were associated with subjective well-being and how happy a person reports to be in life. In addition 2 and 11 gene variants were associated with depressive symptoms and neuroticism, respectively. Of interest, the authors found enrichment of central nervous system-related gene variants for all three phenotypes and of adrenal/pancreas for subjective well-being and depressive symptoms. The adrenal glands produce several hormones, including cortisol, epinephrine, and norepinephrine, involved in the bodily regulation of mood and stress. While the reported associations were strong at the statistical significance level, the size of the associations was small compared to modifiable determinants of happiness constructs.

\subsubsection{A second research question is whether happiness and well-being are independent risk factors for poor health and mortality}

Being unhappy is related to poor health. This can be the result of a direct effect of being unhappy on morbidity and mortality or due to the effect of being unhappy on poor lifestyle. According to data from the large, prospective UK Million Women study being happy or being unhappy was not associated with overall mortality beyond its influence on behavioral risk factors and beyond its association with poor health at baseline (Liu et al. 2016). To investigate the influence of well-being phenotypes on disease-specific morbidity rather than mortality, Mendelian randomization approaches could be envisaged based on genetic variants identified in the recent GWAS on well-being-related sub-phenotypes (Okbay et al. 2016). The association of well-being-related gene variants as instrumental variable rather than of the well-being phenotype itself with the chronic disease risk of interest would be interrogated.

\subsubsection{A third research question is about the molecular mechanisms mediating the effect of well-being on chronic disease outcomes}

In following up on the meet-in-the-middle approach described above toward understanding the happiness exposome, an equivalent approach can also be applied toward understanding the happiness-related phenome, with well-being phenotypes now being the "exposure" and the chronic disease of interest the outcome. Of interest in that respect would be the agnostic study of the well-being-related methylome. The first epigenome-wide association study (EWAS) on well-being was recently published in subjects of the longitudinal survey studies of the Netherlands Twin Register (NTR). The interrogation of more than 400,000 DNA methylation signals for association with well-being pointed to an enrichment of methylation signals related to several central nervous system categories (Baselmans et al. 2015). If the well-being-associated methylation signals were also related to chronic disease 
outcomes, this could inform about biological mechanisms mediating health effects of well-being. Epigenetic studies on DNA methylation are also promising for studying transgenerational aspects of well-being. Stress- and well-being-related methylation signals may be passed on from one generation to the next. The methylation of FKBP5, an important regulator of the glucocorticoid receptor, was recently found to be altered both in holocaust survivors and their adult offspring, pointing to a transgenerational effect of preconception parental trauma (Yehuda et al. 2016).

\section{Conclusions}

Being one of the pillars of personalized health and medicine, -omics biomarkers have become important instruments for epidemiological studies into the possible causes and consequences of health, well-being, and diseases. They allow overcoming some of the limitations of observational research and form magnifying glasses for looking into the potential molecular basis of health and happiness determinants. Research into the primary prevention of chronic diseases and into the maintenance of happiness and well-being becomes increasingly important in the light of a global population that is increasing in number, undergoes demographic aging, and is facing an associated global non-communicable disease (NCD) epidemic. The costs for the treatment of NCDs will be overwhelming the healthcare systems in low- and middle-income countries, and the advent of increasingly expensive personalized treatments for these NCDs is already starting to challenge healthcare systems in high-income countries. It is therefore important that happiness and well-being research is becoming recognized as an important aspect of personalized health.

Acknowledgements The author's research group is supported by the Swiss National Science Foundation Grant Number 33CS30_148470/2.

\section{Compliance with ethical standards}

The current publication is a review of the literature and does not involve human participants and informed consent.

Conflict of interest The author declares that she has no conflict of interest.

Open Access This article is distributed under the terms of the Creative Commons Attribution 4.0 International License (http://creativecommons.org/licenses/by/4.0/), which permits unrestricted use, distribution, and reproduction in any medium, provided you give appropriate credit to the original author(s) and the source, provide a link to the Creative Commons license, and indicate if changes were made.

\section{References}

Abettan C (2016) Between hype and hope: What is really at stake with personalized medicine? Med Health Care Philos 19(3):423-430. doi:10.1007/s11019-016-9697-2 
Ailshire JA, Beltrán-Sánchez H, Crimmins EM (2015) Becoming centenarians: disease and functioning trajectories of older US Adults as they survive to 100. J Gerontol A Biol Sci Med Sci 70(2):193-201. doi:10.1093/gerona/glu124 (Epub 2014 Aug 18)

Bartels M (2015) Genetics of wellbeing and its components satisfaction with life, happiness, and quality of life: a review and meta-analysis of heritability studies. Behav Genet 45(2):137-156. doi:10.1007/ s10519-015-9713-y (Epub 2015 Feb 26)

Baselmans BM, van Dongen J, Nivard MG, Lin BD, Zilhão NR, Boomsma DI, Bartels M, BIOS Consortium (2015) Epigenome-Wide association study of wellbeing. Twin Res Hum Genet 18(6):710-719

Black DS, Cole SW, Irwin MR, Breen E, St Cyr NM, Nazarian N, Khalsa DS, Lavretsky H (2013) Yogic meditation reverses $\mathrm{NF}-\kappa \mathrm{B}$ and IRF-related transcriptome dynamics in leukocytes of family dementia caregivers in a randomized controlled trial. Psychoneuroendocrinology 38(3):348-355. doi:10.1016/j.psyneuen.2012.06.011

Chadeau-Hyam M, Athersuch TJ, Keun HC, De Iorio M, Ebbels TM, Jenab M, Sacerdote C, Bruce SJ, Holmes E, Vineis P (2011) Meeting-in-the-middle using metabolic profiling —a strategy for the identification of intermediate biomarkers in cohort studies. Biomarkers 16(1):83-88. doi:10.3109/ 1354750X.2010.533285

Chellappa SL, Viola AU, Schmidt C, Bachmann V, Gabel V, Maire M, Reichert CF, Valomon A, Landolt HP, Cajochen C (2014) Light modulation of human sleep depends on a polymorphism in the clock gene Period3. Behav Brain Res 271:23-29. doi:10.1016/j.bbr.2014.05.050

Das A (2016) Psychosocial distress and inflammation: Which way does causality flow? Soc Sci Med 170:1-8. doi:10.1016/j.socscimed.2016.10.001

Espie CA, Luik AI, Cape J, Drake CL, Siriwardena AN, Ong JC, Gordon C, Bostock S, Hames P, Nisbet M, Sheaves B, G Foster R, Freeman D, Costa-Font J, Emsley R, Kyle SD (2016) Digital cognitive behavioural therapy for insomnia versus sleep hygiene education: the impact of improved sleep on functional health, quality of life and psychological well-being. Study protocol for a randomised controlled trial. Trials 17(1):257. doi:10.1186/s13063-016-1364-7

Festa A, D’Agostino RJ, Williams K, Karter A, Mayer-Davis E, Tracy R et al (2001) The relation of body fat mass and distribution to markers of chronic inflammation. Int $\mathbf{J}$ Obes Relat Metab Disord 25(10):1407-1415. doi:10.1038/sj.ijo.0801792

Foraster M (2013) Is it traffic-related air pollution or road traffic noise, or both? Key questions not yet settled! Int J Public Health 58(5):647-648. doi:10.1007/s00038-013-0500-3

Franceschi C, Campisi J (2014) Chronic inflammation (inflammaging) and its potential contribution to age-associated diseases. J Gerontol A Biol Sci Med Sci 69(Suppl 1):S4-S9

Frank K, Hou F, Schellenberg G (2015) Life satisfaction among recent immigrants in Canada: comparisons to source-country and host-country populations. J Happiness Stud. doi:10.1007/ s10902-015-9664-2

Gabriel KM, Kuechly HU, Falchi F, Wosniok W, Hölker F (2017) Resources of dark skies in German climatic health resorts. Int J Biometeorol 61(1):11-22

Hamer M, Chida Y (2011) Life satisfaction and inflammatory biomarkers: the 2008 Scottish health survey. Jpn Psychol Res 53(2):133-139. doi:10.1111/j.1468-5884.2011.00460.x

Harb F, Hidalgo MP, Martau B (2015) Lack of exposure to natural light in the workspace is associated with physiological, sleep and depressive symptoms. Chronobiol Int 32(3):368-375. doi:10.3109/ 07420528.2014.982757 (Epub 2014 Nov 26)

Hollands GJ, French DP, Griffin SJ, Prevost AT, Sutton S, King S, Marteau TM (2016) The impact of communicating genetic risks of disease on risk-reducing health behaviour: systematic review with meta-analysis. BMJ 352:i1102. doi:10.1136/bmj.i1102

Irwin MR, Olmstead R, Breen EC, Witarama T, Carrillo C, Sadeghi N, Arevalo JM, Ma J, Nicassio P, Ganz PA, Bower JE, Cole S (2014) Tai chi, cellular inflammation, and transcriptome dynamics in breast cancer survivors with insomnia: a randomized controlled trial. J Natl Cancer Inst Monogr 50:295-301. doi:10.1093/jncimonographs/lgu028

Janicki-Deverts D, Cohen S, Doyle WJ, Turner RB, Treanor JJ (2007) Infection-induced proinflammatory cytokines are associated with decreases in positive affect, but not increases in negative affect. Brain Behav Immun 21(3):301-307

Lambert KG, Nelson RJ, Jovanovic T, Cerdá M (2015) Brains in the city: neurobiological effects of urbanization. Neurosci Biobehav Rev 58:107-122. doi:10.1016/j.neubiorev.2015.04.007 
Levine ME, Cole SW, Weir DR, Crimmins EM (2015) Childhood and later life stressors and increased inflammatory gene expression at older ages. Soc Sci Med 130:16-22. doi:10.1016/j.socscimed.2015. 01.030

Liu B, Floud S, Pirie K, Green J, Peto R, Beral V, Million Women Study Collaborators (2016) Does happiness itself directly affect mortality? The prospective UK Million Women Study. Lancet 387(10021):874-881

McAlpine CS, Swirski FK (2016) Circadian influence on metabolism and inflammation in atherosclerosis. Circ Res 119(1):131-141. doi:10.1161/CIRCRESAHA.116.308034

McEwen BS, Stellar E (1993) Stress and the individual. Mechanisms leading to disease. Arch Intern Med 153:2093-2101

Mehrdadi A, Sadeghian S, Direkvand-Moghadam A, Hashemian A (2016) Factors affecting happiness: a cross-sectional study in the Iranian youth. J Clin Diagn Res 10(5):VC01-VC03. doi:10.7860/JCDR/ 2016/17970.7729

Menni C, Metrustry SJ, Mohney RP, Beevers S, Barratt B, Spector TD, Kelly FJ, Valdes AM (2015) Circulating levels of antioxidant vitamins correlate with better lung function and reduced exposure to ambient pollution. Am J Respir Crit Care Med 191(10):1203-1207. doi:10.1164/rccm.2014112059LE

Münzel T, Sørensen M, Gori T, Schmidt FP, Rao X, Brook FR, Chen LC, Brook RD, Rajagopalan S (2016) Environmental stressors and cardio-metabolic disease: part II-mechanistic insights. Eur Heart J. doi:10.1093/eurheartj/ehw294

Nowakowski ACH (2014) Chronic inflammation and quality of life in older adults: across-sectional study using biomarkers to predict emotional and relational outcomes. Health Qual Life Outcomes 12(1):141. doi:10.1186/s12955-014-0141-0

Okbay A, Baselmans BM, De Neve JE, Turley P, Nivard MG, Fontana MA, Meddens SF, Linnér RK, Rietveld CA, Derringer J, Gratten J, Lee JJ, Liu JZ, de Vlaming R, Ahluwalia TS, Buchwald J, Cavadino A, Frazier-Wood AC, Furlotte NA, Garfield V, Geisel MH, Gonzalez JR, Haitjema S, Karlsson R, van der Laan SW, Ladwig KH, Lahti J, van der Lee SJ, Lind PA, Liu T, Matteson L, Mihailov E, Miller MB, Minica CC, Nolte IM, Mook-Kanamori D, van der Most PJ, Oldmeadow C, Qian Y, Raitakari O, Rawal R, Realo A, Rueedi R, Schmidt B, Smith AV, Stergiakouli E, Tanaka T, Taylor K, Wedenoja J, Wellmann J, Westra HJ, Willems SM, Zhao W; LifeLines Cohort Study, Amin N, Bakshi A, Boyle PA, Cherney S, Cox SR, Davies G, Davis OS, Ding J, Direk N, Eibich P, Emeny RT, Fatemifar G, Faul JD, Ferrucci L, Forstner A, Gieger C, Gupta R, Harris TB, Harris JM, Holliday EG, Hottenga JJ, De Jager PL, Kaakinen MA, Kajantie E, Karhunen V, Kolcic I, Kumari M, Launer LJ, Franke L, Li-Gao R, Koini M, Loukola A, Marques-Vidal P, Montgomery GW, Mosing MA, Paternoster L, Pattie A, Petrovic KE, Pulkki-Råback L, Quaye L, Räikkönen K, Rudan I, Scott RJ, Smith JA, Sutin AR, Trzaskowski M, Vinkhuyzen AE, Yu L, Zabaneh D, Attia JR, Bennett DA, Berger K, Bertram L, Boomsma DI, Snieder H, Chang SC, Cucca F, Deary IJ, van Duijn CM, Eriksson JG, Bültmann U, de Geus EJ, Groenen PJ, Gudnason V, Hansen T, Hartman CA, Haworth CM, Hayward C, Heath AC, Hinds DA, Hyppönen E, Iacono WG, Järvelin MR, Jöckel KH, Kaprio J, Kardia SL, Keltikangas-Järvinen L, Kraft P, Kubzansky LD, Lehtimäki T, Magnusson PK, Martin NG, McGue M, Metspalu A, Mills M, de Mutsert R, Oldehinkel AJ, Pasterkamp G, Pedersen NL, Plomin R, Polasek O, Power C, Rich SS, Rosendaal FR, den Ruijter HM, Schlessinger D, Schmidt H, Svento R, Schmidt R, Alizadeh BZ, Sørensen TI, Spector TD, Steptoe A, Terracciano A, Thurik AR, Timpson NJ, Tiemeier H, Uitterlinden AG, Vollenweider P, Wagner GG, Weir DR, Yang J, Conley DC, Smith GD, Hofman A, Johannesson M, Laibson DI, Medland SE, Meyer MN, Pickrell JK, Esko T, Krueger RF, Beauchamp JP, Koellinger PD, Benjamin DJ, Bartels M, Cesarini D (2016) Genetic variants associated with subjective well-being, depressive symptoms, and neuroticism identified through genome-wide analyses. Nat Genet 48(6):624-633. doi:10.1038/ng.3552

Pepys MB, Hirschfield GM (2003) C-reactive protein: a critical update. J Clin Invest 111(12):1805-1812. doi:10.1172/JCI200318921

Poldrack RA, Laumann TO, Koyejo O, Gregory B, Hover A, Chen MY, Gorgolewski KJ, Luci J, Joo SJ, Boyd RL, Hunicke-Smith S, Simpson ZB, Caven T, Sochat V, Shine JM, Gordon E, Snyder AZ, Adeyemo B, Petersen SE, Glahn DC, Reese Mckay D, Curran JE, Göring HH, Carless MA, Blangero J, Dougherty R, Leemans A, Handwerker DA, Frick L, Marcotte EM, Mumford JA (2015) Long-term neural and physiological phenotyping of a single human. Nat Commun 6:8885. doi:10. 1038/ncomms 9885 
Probst-Hensch NM (2010) Chronic age-related diseases share risk factors: do they share pathophysiological mechanisms and why does that matter? Swiss Med Wkly 140:w13072. doi:10.4414/smw. 2010.13072

Rappaport SM (2016) Genetic factors are not the major causes of chronic diseases. PLoS ONE 11(4):e0154387. doi:10.1371/journal.pone.0154387 (eCollection 2016)

Recio A, Linares C, Banegas JR, Díaz J (2016) Road traffic noise effects on cardiovascular, respiratory, and metabolic health: an integrative model of biological mechanisms. Environ Res 146:359-370. doi:10.1016/j.envres.2015.12.036

Rius-Ottenheim N, de Craen AJ, Geleijnse JM, Slagboom PE, Kromhout D, van der Mast RC, Zitman FG, Westendorp RG, Giltay EJ (2012) C-reactive protein haplotypes and dispositional optimism in obese and nonobese elderly subjects. Inflamm Res 61(1):43-51. doi:10.1007/s00011-011-0387-5 (Epub 2011 Oct 7)

Shenker NS, Polidoro S, van Veldhoven K, Sacerdote C, Ricceri F, Birrell MA, Belvisi MG, Brown R, Vineis P, Flanagan JM (2013) Epigenome-wide association study in the European Prospective Investigation into Cancer and Nutrition (EPIC-Turin) identifies novel genetic loci associated with smoking. Hum Mol Genet 22(5):843-851. doi:10.1093/hmg/dds488

Sithey G, Wen LM, Kelly P, Li M (2017) Association between sleep duration and self-reported health status: findings from the Bhutan's gross national happiness study. J Clin Sleep Med 13(1):33-38

Sprangers MA, Bartels M, Veenhoven R, Baas F, Martin NG, Mosing M, Movsas B, Ropka ME, Shinozaki G, Swaab D, GENEQOL Consortium (2010) Which patient will feel down, which will be happy? The need to study the genetic disposition of emotional states. Qual Life Res 19(10):1429-1437

Sprangers MA, Thong MS, Bartels M, Barsevick A, Ordoñana J, Shi Q, Wang XS, Klepstad P, Wierenga EA, Singh JA, Sloan JA (2014) GeneQol Consortium. Biological pathways, candidate genes, and molecular markers associated with quality-of-life domains: an update. Qual Life Res 23(7):1997-2013. doi:10.1007/s11136-014-0656-1

Steptoe A, O’Donnell K, Badrick E, Kumari M, Marmot M (2008) Neuroendocrine and inflammatory factors associated with positive affect in healthy men and women: the Whitehall II study. Am J Epidemiol 167(1):96-102

Steptoe A, Deaton A, Stone AA (2015) Subjective wellbeing, health, and ageing. Lancet 385(9968):640-648. doi:10.1016/S0140-6736(13)61489-0

Topol EJ (2014) Individualized medicine from prewomb to tomb. Cell 157(1):241-253

Tuck NL, Grant RC, Jackson A, Brooks AE, Consedine NS (2016) Beyond self-report: performance measures of emotional competencies predict symptoms of depression and anxiety, physical symptoms, self-rated health, and immunoregulatory molecules. Ann Behav Med 50(6):823-835

van den Berg F, Verhagen C, Uitenbroek D (2015) The relation between self-reported worry and annoyance from air and road traffic. Int J Environ Res Public Health 12(3):2486-2500. doi:10.3390/ ijerph120302486

Vineis P, Chadeau-Hyam M, Gmuender H, Gulliver J, Herceg Z, Kleinjans J, Kogevinas M, Kyrtopoulos S, Nieuwenhuijsen M, Phillips DH, Probst-Hensch N, Scalbert A, Vermeulen R, Wild CP, EXPOsOMICS Consortium (2016) The exposome in practice: design of the EXPOsOMICS project. Int J Hyg Environ Health. doi:10.1016/j.ijheh.2016.08.001

Weiss A, Baselmans BM, Hofer E, Yang J, Okbay A, Lind PA, Miller MB, Nolte IM, Zhao W, Hagenaars SP, Hottenga JJ, Matteson LK, Snieder H, Faul JD, Hartman CA, Boyle PA, Tiemeier H, Mosing MA, Pattie A, Davies G, Liewald DC, Schmidt R, De Jager PL, Heath AC, Jokela M, Starr JM, Oldehinkel AJ, Johannesson M, Cesarini D, Hofman A, Harris SE, Smith JA, Keltikangas-Järvinen L, Pulkki-Råback L, Schmidt $\mathrm{H}$, Smith J, Iacono WG, McGue M, Bennett DA, Pedersen NL, Magnusson PK, Deary IJ, Martin NG, Boomsma DI, Bartels M, Luciano M (2016) Personality polygenes, positive affect, and life satisfaction. Twin Res Hum Genet 19(5):407-417. doi:10.1017/ thg.2016.65 (Epub 2016 Aug 22)

Wenzel SE (2016) Emergence of biomolecular pathways to define novel asthma phenotypes. Type-2 immunity and beyond. Am J Respir Cell Mol Biol 55(1):1-4. doi:10.1165/rcmb.2016-0141PS

Wild CP (2005) Complementing the genome with an "exposome": the outstanding challenge of environmental exposure measurement in molecular epidemiology. Cancer Epidemiol Biomark Prev $14: 1847-1850$ 
Yehuda R, Daskalakis NP, Bierer LM, Bader HN, Klengel T, Holsboer F, Binder EB (2016) Holocaust exposure induced intergenerational effects on FKBP5 methylation. Biol Psychiatry 80(5):372-380

Yurtsever T, Schilling TM, Kölsch M, Turner JD, Meyer J, Schächinger H, Schote AB (2016) The acute and temporary modulation of PERIOD genes by hydrocortisone in healthy subjects. Chronobiol Int 2:1-13 (Epub ahead of print) 